\title{
Instilling a Sense of Civic Responsibility in Engineering Students Through Technical Communication
}

\author{
Julia M. Williams, Ph.D. \\ Associate Professor of English and Coordinator of Technical Communication \\ Department of Humanities and Social Sciences \\ Rose-Hulman Institute of Technology
}

In his address to the 23rd Annual American Association for the Advancement of Science Colloquium on Science and Technology, Neal Lane, assistant for science and technology to then President Bill Clinton and director of the White House Office of Science and Technology Policy, argued that historically scientists and engineers have always played a significant, albeit particular, role in society. Possessing knowledge of science and technology, engineers have acted on behalf of society, developing and implementing beneficial technologies that serve the needs of individuals and their communities. Lane suggests that more recently, the nature of the engineer's role has been changing, creating a new and additional function that engineers and scientists must play in society:

I termed this role the "civic scientist," with civic meaning "concerning or affecting the community or the people." In this new civic capacity, scientists and engineers step beyond their campuses, laboratories, and institutes into the center of their communities to engage in active dialogue with their fellow citizens. Do I mean that we go out and teach science to shopkeepers, lawyers, consultants, and construction workers? Not entirely.

To engage in dialogue is to listen as well as to speak. While there is great need for the public to have a better understanding of science, and we should promote this in every way possible, there is as great a need for scientists to have a better understanding of the public. ${ }^{1}$ (my emphasis)

Lane argues here for a reciprocal understanding between the engineer and society, a dialogue in which the engineer listens to society's needs and interprets them in the design of new and beneficial technologies. The argument for a civic-minded engineer will seem very familiar to those of us who have been working in the field of engineering education. As a result of the demands of The Accreditation Board for Engineering and Technology's Engineering Criteria 2000, engineering faculty know that if they wish their programs to remain accredited, they must graduate students who possess "an understanding of professional and ethical responsibility" (f), as well as "the broad education necessary to understand the impact of engineering solutions in a global and societal context" (h) and (g) "an ability to communicate effectively". ${ }^{2}$ These attributes resemble the very same that Lane proposes. Engineering curricular revision represents a movement toward instilling a sense of ethical responsibility and awareness of social issues in engineering students, and such revision is now underway in many engineering programs and department across the United States. Engineering education reform is not unique in making this effort; in liberal arts colleges, in large comprehensive universities, in higher education in general, 
faculty are attempting to remedy student apathy and lack of community involvement with community-based, rather than strictly classroom-based, learning. As a recent Kellogg Commission report states, "the biggest educational challenge we face revolves around developing character, conscience, citizenship, tolerance, civility, and individual and social responsibility in our students." ${ }^{3}$

Clearly the effort to improve engineering students' ethical awareness is part of a national trend in education, but we should not overlook the fact that, as Neal Lane observed, the role of engineers in society is unique. As stewards of technology, engineers design, develop, and maintain the mechanisms that make civil society possible, not just the businesses and factories, but city government services like roads and bridges, medical technologies, and countless others. Thus, when we guide engineering students as they develop character, conscience, and social responsibility, we recognize the fact that these qualities will play out in the use and/or abuse of technology in our society. Engineering programs, therefore, do more than graduate responsible citizens; they graduate responsible citizens who determine the future of technology.

Given the nature of the engineer's role in society, I would argue that the current solutions to the problem-increasing the level of ethics instruction and/or increasing the number of service learning projects students complete in the engineering curriculum-ignore the central role of communication in the success or failure of the engineer to address society's needs, to both speak and listen to what society demands of technology. This paper considers the rhetorical nature of the engineer's work and his/her relation to society and offers one view of developing students' sense of civic responsibility through instruction in communication as part of curricular revision.

\section{Ethics Instruction in the Engineering Curriculum}

While there appears to be general agreement about the need to graduate students with a greater sense of their responsibilities to society, there is less agreement regarding how this outcome may be achieved. How do we train engineering students in particular to recognize the role they play in meeting society's needs, to see their technical work as a civic responsibility? So far the answers have been focused primarily on ethics and service learning. If students need to learn to be responsible to society, the arguments go, then students need to take more courses in ethics and/or take courses that feature a service learning dimension.

Ethics education for engineering students has gained new stature in the past fifteen years, spawning a movement to encourage engineering faculty to add ethical dimensions to their technical courses. Resources for faculty are available at The Online Ethics Center for Engineering and Science. According to Whitbeck, the best approach to teaching ethics to engineering students is to adopt a "'hands on,' 'practice-oriented,' 'experiential,' or 'active learning approach":

The active learning exercises should be chosen so that over the course of their undergraduate career students engage in developing a full range of ethical skills. These include not only making judgments about whether some action is ethical, or which of a set of multiple choices is the best (or least bad), but skills such as the ability to:

- Find statements of ethical standards by reputable bodies and evaluate the legitimacy of those standards 
- Conduct an ongoing assessment of a problem in a way that does not cause unnecessary harm (e.g., destroy a person's reputation)

- Recognize explanations other than the one that appears most likely

- Fashion responses that will be robust in the sense that they will be wise, even if the situation turns out to be other than the one that seemed most plausible

- Recognize when the moral territory is unfamiliar and locate good advice about how to proceed and the likely effects of doing so. ${ }^{4}$

While there is evidence that ethics have been added at each level of the curricula in many programs, perhaps the most remarked upon site for addition has been in the capstone engineering design course. A survey conducted by faculty at the Brigham Young University College of Engineering and Technology demonstrates that the effort to include ethics instruction was already gaining momentum in 1995. Responses from 360 engineering departments in North American showed that ethics were taught in more than $40 \%$ of all capst one engineering design courses. Topics taught at higher percentages were as follows: Oral Presentations (61\%); Creativity, Concept Generation (48\%); Teamwork Essentials (44\%); and Project Planning and Scheduling (42\%). Engineering Economics (40\%) and Ethics were tied. ${ }^{5}$ Absent from the Brigham Young survey, however, is information regarding the nature of the instruction offered to students. Survey respondents were not required to assess the quality of instruction in ethics offered to students in the capstone course: were ethics an explicit learning goal of the course; were students given opportunities to demonstrate their learning in ethics in the course (through tests, reports, etc.); were students given feedback on their learning from the professor. Theoretically, one guest lecture by a philosophy professor could have constituted ethics instruction for any of the capstone courses reported on in the survey.

In order to increase the likelihood that students receive more intensive instruction from a content expert, some may argue that students should be required to take more ethics courses. These courses would take ethics as their primary focus, not as an associated topic that must compete with other concerns in the context of a capstone design course. My objection here, however, relates to the current structure of most engineering programs. Requiring students to take additional courses in ethics may indeed help them develop a sense of social awareness. Unfortunately adding more required courses to an already requirement-heavy curriculum seems unlikely. Engineering faculty currently argue that technical courses may be threatened by any addition to the curriculum; other concerns relate to personnel (hiring more faculty to teach ethics courses) or engineering faculty development (training engineering faculty so they can include an ethical dimension to their technical courses). Furthermore, ethics courses that remain separate from technical content, such as those that may be taught by the university philosophy department, may do little to demonstrate to engineering students the relation of technical work to larger social concerns.

In the final analysis, increasing student contact with ethics topics or adding ethics courses to the curriculum will not resolve the crucial problem that lies at the center of the civic responsibility issue. Training in practical ethics does help students assess the ethical dimensions of a particular technical decision they must make. Applied ethics does not, however, address the role that the engineer plays in the conduct of society, specifically in the management and development of technology, as well as the taking of a leadership role in familiarizing the rest of society with 
relative merits of particular technologies. As Wheeler and McDonald have argued, "[o]ur goal can be to provide our students with a rigorous technical education while, at the same time, providing them with the tools necessary for them to become leaders and decision-makers in society." 6

\section{Service-Learning Projects in the Engineering Curriculum}

If the ethics curriculum is not the answer, then we may look to the rapidly growing field of service-learning for an alternative solution. If students need to become more aware of their role in society, then a project that matches students with community organizations should help students gain a fuller sense of society's needs.

According to the National and Community Service Act of 1990, service-learning is defined as an education method:

- under which students learn and develop through active participation in ...thoughtfully organized service experiences that meet actual community needs;

- that is integrated into the students' academic curriculum or provides structured time for a student to think, talk, or write about what the student did and saw during the service activity;

- that provides students with opportunities to use newly acquired skills and knowledge in real-life situations in their own communities; and

- that enhances what is taught in school by extending student learning beyond the classroom and into the community and helps to foster the development of a sense of caring for others. ${ }^{7}$

In contrast to an ethics course, service-learning projects place students into their communities, linking classroom learning with interaction with not-for-profit organizations that need assistance. For engineering programs, service-learning takes the form of capstone design projects provided by community organization clients, rather than industry or business. A program like ProCEED in the Mechanical Engineering department at the University of Michigan is typical of this approach. The Program for Civic Engagement in Engineering Design (ProCEED) requires that students "solicit projects from the surrounding community for development and prototyping in the senior design course." As a result of creating useful designs that meet community needs, students benefit by "learning to interact with community sponsors, usually without technical training ... [s]tudents also benefit by learning to use their engineering skills to solve everyday problems in a community service capacity. ${ }^{8}$ Programs like this are under development in many engineering programs across the country.

The question remains, do service-learning methods demonstrate to students their social/technical role as engineers? At this point, there have not been enough quantitative studies completed that can answer this question. Preliminary findings suggest, however, that the impact of servicelearning projects on students is definitely mixed. As Adler-Kassner, Crooks, and Watters have argued, "the term 'service' lends itself to a feeling of superiority, and students therefore approach service learning with an established ideological perspective." Certainly students approach all their work with a particular perspective, but in the case of service-learning, the perspective colors the experience almost completely: 
Perhaps students who see service learning as altruistic close the door on the possibility of a reciprocal relationship, and this prevents them from gaining critical social consciousness. Of perhaps students who draw a hierarchical boundary and assign roles, labeling themselves as "givers" and others as "needy" may have difficulty developing habits of ethical interaction. ${ }^{10}$

Engineering students may see their role in the project as the technical expert who "knows best" regarding the solution to the organization's problem. In this way, service-learning projects may only reinforce, rather than remedy, the disconnection between the technical expert and his/her society.

\section{The Rhetorical Dimensions of Civic Responsibility}

While I am not dismissing the importance of ethics and service-learning to the education of engineers, I do wish to emphasize a dimension of the question that has, so far, received little attention. Although we wish to help engineering students develop their skills in listening and responding to society's needs for technological development, we have not paid adequate attention to the rhetorical nature of the problem. As Neal Lane's comments suggest, the mode of interaction between the engineer and society is communication, whether in written reports to clients, oral presentations to town governments, or speeches at public meetings. As such, the difficulties engineers experience in relating to society at large, whether with design clients who are outside their own organization or with non-technical individuals who are effected by technological development, stem largely from their misreading of the rhetorical situation in which they must speak and work. Part of the difficulty comes from the nature of the engineering profession itself. Working in a "technically-oriented discourse community where designs [are] given primacy," engineers are often unaware of the rhetorical aspects of their profession; instead, designs are considered "self-explanatory," a fact that makes many engineers unwilling to explore the persuasive features of their projects. ${ }^{11}$ Furthermore, as Winsor has demonstrated,

Unless there is a problem, rhetoric remains invisible because agreement has been readied in the smooth interaction of everyday practice. Problems arise when things break down or at the boundary between different kinds of expertise, where an expert in one area is likely to have trouble understanding an expert in another. ${ }^{12}$

My suggestion, therefore, is to consider communication instruction, particularly rhetorical analysis, as a more effective method of showing students both their civic role and the means of improving their negotiations of technical developments with society.

The following assignment, developed in a course on technical communication, illustrates the inherent difficulties in foregrounding rhetoric to engineering students. In developing and making the assignment, I found that the Poster Session was an effective way to introduce the concepts of civic responsibility in the context of technical information. Students are required to select a technical topic that relates to their major course of study. After conducting library research on this topic, during which they are supposed to familiarize themselves with the technology and its current developments, students are asked to prepare a brief, informal presentation and poster (see below). 


\section{Poster Session Assignment}

The poster session will provide you with the opportunity to use the technical content you learned in your Technical Review to produce a poster and explain the topic to a wide audience. You may choose to offer an overview of the topic, or you may choose to focus on some smaller segment of the content area (choose carefully!). The main components of the assignment are the poster itself, a 3-5 minute accompanying oral explanation of the poster, and answering questions. The poster presentation is a common genre in business and professional as well as academic settings.

\section{Logistics:}

Your poster will be displayed in the Union all day on one designated date. You will be required to appear with your poster during the usual class hour. People will wander through the poster session area and stop to observe various posters at will. Also, you will sign up for a 7 -minute slot (sometime during that same day) during which I will grade your poster and your presentation of it. When it is your designated time to be graded, give me a little wave to help me find you quickly if the area is crowded.

Audience: anyone in the Union (students, faculty, staff, etc.)

Topic: derived from literature review assignment

Purpose: teach people with varying degrees of technical knowledge about a technical subject

\section{Tips for posters:}

- Don't forget your name and your title.

- All type and visuals need to be visible from at least $4 \mathrm{ft}$ away.

- Format and material is at your discretion. You might use posterboard or covered cardboard, you might use the special printer in Meyers Building that can print poster size, you might have a flat rectangular poster or a winged poster, you may add 3-dimensional items to your poster if desired, you may bring accompanying demonstration material (props) as desired. There will be tables and easels available.

- Use all of the poster, avoiding unbalanced "white" space.

- Integrate text and visuals.

- Provide a clear sense of arrangement or progression for the eye around the poster.

- Do NOT print out paragraphs (such as from your literature review) in a larger font and then paste then on your poster. Consider using formats such as bulleted lists to keep the poster easily scannable.

- Do all you can to make the poster appear neat and professional. For example, avoid ragged cutting edges, and consider using background frames/mats for sections

\section{Tips for oral presentation accompanying poster:}

- Prepare a 3-5 minute "spiel" that walks your audience through the poster.

- Don't start at too specific a level of abstraction.

- Try to connect to the specific audience in front of you, preferably at the beginning. Highlight why they should care about this topic. Perhaps use analogies they can relate to, and other audience accommodation strategies.

- Be very careful to either avoid technical jargon, or, when needed, to translate it for your audience unless you are sure they are already familiar with the terms. Don't be afraid to ask quick but polite questions to determine the expertise level of your audience.

- Speak with sufficient volume to be heard over background noise.

- Be enthusiastic.

- Don't rush, and don't waste time scrambling for thoughts or words. Practice the spiel beforehand, but be ready to adjust it as needed on the spot. Accept interruptions gracefully.

- Listen closely to any questions posed by the audience, and answer them to the best of your ability. Don't try to bluff your way through answers. When appropriate, seize opportunities to learn from any knowledgeable audience members by asking questions of your own.

The poster presentation is worth $10 \%$ of your final course grade. 
Unlike other assignments in the course, which allow students to write for an audience with a similar engineering background to their own, the Poster Session is designed to accommodate a general audience with little technical training or knowledge. In order to reinforce the efforts students are to make regarding audience accommodation, I schedule the Poster Session during the middle of the day in the Student Union building on our campus. From approximately 11:00 A.M. to 2:00 P.M., students, faculty, and staff from all areas of the campus converge for lunch, and the posters are set up so that the campus community walking by is invited to stop and chat with the student presenters. In order to describe and discuss their topic, students have to adapt quickly to the technical background of their constantly varying audience, from technical faculty outside of their majors one moment, to staff members from administrative offices the next, and then first-year students.

As is often the case with open-ended assignments like this one, students usually voice their worries about performing successfully on the Poster Session. They are concerned with the graphical nature of the poster, what technologies were available that may help them produce a successful poster, and how long they should plan on speaking to their audiences. But perhaps the most revealing comment on the assignment came from a student who wondered how he was supposed to present technical information to a non-technical audience. His question in class was, "How dumb do you want me to write it?" I found this question an important one, since it revealed so much of the student's conceptualization of the problem at hand. In his mind, I believe, the effort of audience accommodation represented a particular hierarchy of technical understanding, with the student engineer diluting technical information to a degree that would make it comprehensible to a $4^{\text {th }}$ grade student. Making technical information clear to his audience was not for this student a matter of providing necessary definitions, explaining background theory, or relying on graphics that illustrated principles. For this student, relating technical information to an audience constituted a simplification of facts for listeners too "dumb" to understand.

Some may dismiss the student's remark as an exception, a smart-aleck comment not to be considered seriously. I find, however, that the incident highlights the communication problems that come when student engineers consider the task of communicating technical information to non-technical audiences. As the developers of technologies, students will play an important role in our society, bringing new devices and processes that can potentially save lives and improve daily existence. But we have not addressed the rhetorical nature of technical work, and so student engineers are woefully unprepared to encounter the public in anything but the role of technical "giver" who must assist the technologically "needy."

Rather than argue for more courses in ethics or service-learning, or even more courses in communication, I would argue for the inclusion of assignments like these in technical courses. I believe that engineering faculty can include the principles of rhetorical analysis - audience analysis and accommodation, tailoring technical information for various audiences, examination of sample technical documents as models for students to imitate-in their courses, since many are already committed to including written and oral communication tasks as part of technical course requirements. These principles need not be elaborate or theoretical. Instead, students will get a very clear sense of the persuasive dimension of engineering practice if they are required to 
think more reflectively and critically about their role in society and the function of communication and civic discourse.

\section{Bibliography}

1. Lane, Neal. 1998. "The Civic Scientist and Science Policy." Science and Technology Policy Yearbook. <http://www.aaas.org/spp/yearbook/chap.22.htm>.

2. Accreditation Board for Engineering and Technology. 2000. ABET Homepage http://www.abet.org.

3. Ellis, Martha. 2001. "High-Tech, High Engagement." Community College Week vol. 13, no. 17 (April 2).

4. Whitbeck, Caroline. 2001. "Undergraduate Education in Practical Ethics." The Online Ethics Center for Engineering and Science http://onlineethics.org/edu/cwethed.html.

5. Todd, Robert H., Spencer P. Magleby, Carl D. Sorensen, Bret R. Swan, and David K. Anthony. 1995. "A Survey of Capstone Engineering Courses in North America." Journal of Engineering Education (April): 165-74.

6. Wheeler, Edward, and Robert L. McDonald. 2000. "Writing in Engineering Courses." Journal of Engineering Education (October): 481-86.

7. Belbas, Brad, Kathi Gorak, and Rob Shumer. 1993. "Commonly Used Definitions of Service-Learning: A Discussion Piece." The National Service-Learning Clearinghouse http://www.servicelearning.org/who/def.htm.

8. Stott, Nathaniel W., William W. Schultz, Diann Brei, Deanna M. Winton Hoffman, and Greg Markus. 2000. "ProCEED: A Program for Civic Engagement in Engineering Design." Proceedings of the ASEE Conference.

9. Adler-Kassner, Linda, Robert Crooks, and Ann Watters. 1997. "Service-Learning and Composition at the Crossroads." Writing the Community: Concepts and Models for Service-Learning in Composition. Ed. Linda Adler-Kassner, et. al. Washington DC: 1-17.

10. Matthews, Catherine, and Beverly B. Zimmerman. 1999. "Integrating Service Learning and Technical Communication: Benefits and Challenges." Technical Communication Quarterly vol. 8, no. 4 (Fall): 383-404.

11. Wojahn, Patricia, Julie Dyke, Linda Ann Riley, Edward Hensel, and Stuart C. Brown. 2001. "Blurring Boundaries between Technical Communication and Engineering: Challenges of a Multidisciplinary, Client-Based Pedagogy.” Technical Communication Quarterly vol. 10, no. 2 (Spring ): 129-49.

12. Winsor, Dorothy A. 1998. "'Rhetorical Practices in Technical Work." Journal of Business and Technical Communication vol. 12, no. 3 (July).

\section{Biographical Information}

Julia M. Williams is Associate Professor of English and Coordinator of Technical Communication at Rose-Hulman Institute of Technology, Terre Haute, Indiana. In 1996, she developed the campus-wide Program in Technical Communication, which currently assists all engineering students in developing their communication skills in a variety of technical and non-technical courses. Her articles on writing assessment, electronic portfolios, and ABET have appeared in the Technical Communication Quarterly, Technical Communication: Journal of the Society for Technical Communication, and The International Journal of Engineering Education. 